\title{
Different Substrate Materials for Designing a Passive UHF RFID Tag Antenna
}

\author{
P. Limameren Chang, Garima Saini
}

\begin{abstract}
The Radio Frequency Identification (RFID) technology has been increasingly used for various application such as tracking of products, smart cards, identification, item management, security etc. In this paper, the performance parameter of the passive UHF RFID tag antenna has been studied for four different substrate materials viz., FR4 epoxy, PET, Rogers 4350, Taconic TLY materials. A simple meandered dipole antenna has been designed using a T-match stub for impedance matching of the tag antenna with the attached RFID chip. These different substrates are then designed separately, for the same antenna geometry. The effect of using these substrates on RFID tag antenna parameters such as reflection coefficient, antenna gain, VWSR, radiation pattern, impedance, ease of optimization level, read range, and radiation efficiency are then observed.
\end{abstract}

Index Terms:impedance matching, meander line antenna, tag antenna, UHF RFID

\section{INTRODUCTION}

The RFID is a wireless identification technology that used the electromagnetic fields to detect, track, and control the objects. The main components of RFID consist of a reader system, tag or transponder element, and a separate antennas attached with the reader and the tag. The tag to be attached with an object is connected with a microchip for the purpose of assigning identification information.

The mode of communication between the reader and the tag takes place when these two are correlated with a common frequency band of operation. For RFID, the three frequency band classified are Low Frequency (LF), High Frequency (HF), and Ultra High Frequency (UHF) range. When the tagged object comes in vicinity of the radiating reader antenna, the electromagnetic fields is sensed by the tag antenna. The energy is then harvested and forms a current around the antenna which flows to the microchip. It powers ON the chip, modulating the data contained within its memory and the information stored can be retrieved via backscattering to the reader antenna, and then to the host computer to view the information. Thus the tag antenna using this mechanism forms the basis of a passive type RFID tag system.

Revised Manuscript Received on June 15, 2019.

P. Limameren Chang, Electronics and Communication, National Institute of Technical Teachers Training and Research, Chandigarh, India.

Garima Saini, Electronics and Communication, National Institute of Technical Teachers Training and Research, Chandigarh, India.
A typical commercialized RFID tag antenna construction is as shown in fig. 1. Antenna, matching circuit, Chip, and the substrate comprises the various modules of a RFID tag antenna. The dimensions shown in figure 1 is $98.2 \times 12.3$ $\mathrm{mm}$, which shows the importance of size miniaturization in RFID industry for global market. Tags of such kind should be low cost; since the integration of small micro sized chip IC with the tag tends to be costlier and difficult to fabricate, hindering its full potential for growth in RFID [2].

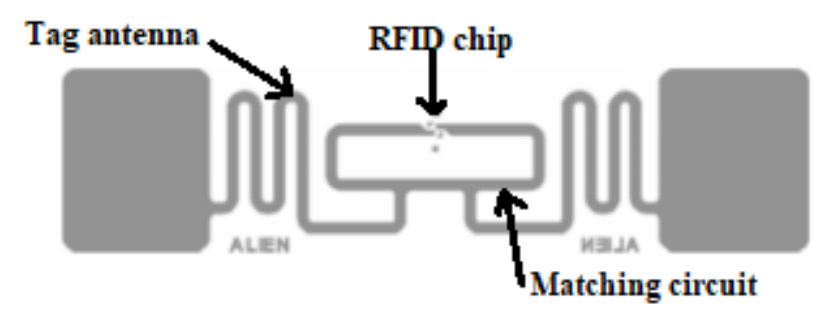

Fig. 1 RFID Tag Modules [1]

Y. He et al. mentions that the fabrication of the chip and the antenna accounts for more than $50 \%$ of the final cost. For miniaturization of antennas, tag antenna is one of the most common area to work on and it is the biggest component from the tag modules [3]. But care has to be taken about the trade-off between the tag antenna and the size, as smaller antenna tends to have smaller read range. Hence a compromise has to be made while designing the antenna

Complex impedance matching has to be the most challenging aspect in designing the RFID tag, since a chip has to be attached to the terminal of the RFID tag antenna and its load impedance is not the same as the normal load impedance of $50 \Omega / 75 \Omega$. For proper transfer of power to the chip, the impedance of the chip should be the complex conjugate with the tag antenna impedance. Also, trying to shrink the design dimension is another aspect to look to, as by reducing the volume of the size of the tag, it results in miniaturization of the tag and indirectly affects the reduction in cost also.

In this paper, the RFID tag antenna is designed for passive UHF band of 865-867 MHz application. The characteristic of the tag antenna is altered by using the different substrate material. A simple meandered line dipole antenna and a T-match stub element is then optimized to generate the maximum performance for different antenna parameters. The performance characteristics of the desired tag antenna designed using different substrate materials are compared. This article has been divided into 6 sections. Section 2 describes the property of four different substrate materials. 
Section 3 describes the meandered line dipole antenna design using a T-match stub matching circuit. The final tag antenna structure after optimization for different substrate are also shown. The simulation results for several antenna parameters and their implications are further discussed in section 4 . The results obtained from the proposed tag antenna design are next summarized in table in section 5. Finally, the concluding remarks are presented in section 6 .

\section{PROPERTIES OF SUBSTRATE}

The first step in designing any antenna is choosing the appropriate substrate. A substrate because of its dielectric material is mainly needed to provide mechanical support to the antenna. Because the dielectric material also affects the electrical performance of the antenna, a right substrate that fulfils the requirements of both the mechanical as well as the electrical properties are to be met. Some of the major properties that need to be evaluated while choosing the substrates are the dielectric constant, loss tangent, variations with temperature and frequency, physical properties during fabrication and thickness uniformity [4]. There are different types of substrate materials available in the market with different properties, because of which there is always some compromise in choosing a particular substrate with the required antenna parameters.

In microstrip antenna design, the selection of right substrate material according to the application is the most important parameter. Use of microstrip antennas can give you limited freedom to work with due to its low gain and efficiency and can be overcome by selecting the proper permittivity of the substrate to control the parameters of the antennas [5]. For designing a high performance antenna with better efficiency, larger bandwidth, and directivity, a thicker substrate with lower dielectric range are preferred. For reducing the losses in radiation, a thin substrate with higher dielectric values are often chosen, but at the sacrifice of radiation efficiency and bandwidth.

Dielectric constant $\left(\varepsilon_{r}\right)$ is the medium for electromagnetic propagation and explains the relationship between electric field and the magnetic field, normally located between the radiating element and the ground plane. It is defined as the ratio of dielectric permittivity of the material with vacuum or dry air.For most PCB materials, its value ranges from 2.5 to 4.5 , and is the critical factor in determining the performance of the antenna. The effect of dielectric constant on frequency of operation is inversely related, and the lower the value of dielectric constant, the better the substrate performs [6].

Another important parameter of a substrate is the Loss tangent or dissipation factor; it is a measure of how much power is lost due to the dielectric material. There is zero loss tangent, when the energy dissipated is zero, the loss tangent is zero and its value tends to infinity as all the energy gets dissipated [7]. A material having the low loss tangent factor can be regarded as having the one with low loss power material [8]. For most common application, the loss tangent value ranges from low loss $(0.02)$ to very low loss $(0.001)$ power. Unlike dielectric constant, the effect of frequency on the loss tangent is inversely proportional. The loss tangent is useful in determining the degree of signal attenuation especially at very high frequencies.

\section{A. FR4}

The name FR stands for "Fire Retardant" that complies with the UL94V-0 standard, thus allowing this material to achieve much greater level of resistance to heat. FR-4 created by NEMA (National Electrical Manufacturers Association) in 1968, is a composite materials composed of woven fiberglass reinforced epoxy resin laminated sheets. FR4 material is most commonly used as an electrical insulator for designing of different antennas. The important characteristics of FR-4 is its mechanical strength due to the presence of fiberglass, excellent insulating properties, and good fabrication characteristics [9]. They have near zero water absorption level with values -0.125 in (less than $10 \%$ ), maximum operating temperature of $140^{\circ} \mathrm{C}$, standard relative permittivity is 4.4. Because of their mechanical strength, reliability, and low cost, FR-4 is the most common choice for antenna design in several applications. But for very high frequency application the choice of FR-4 might not be the ideal case.

\section{B. PET}

Polyethylene terephthalate (PET) is a kind of polymer resin belonging to the polyester family. It is a thin film substrate with semi rigid to rigid structure and is extremely light weight. For industrial use, the PET substrate is measured most suitable to use for UHF and microwave applications [10], making it suitable for printed electronics. PET has attracted a wide array of interest from various researchers for antenna design due to its low cost, good thermal stability, and excellent moisture resistance [11]. There are different varieties of PET substrate material available in the market such as varying density, coating, thickness, texture, etc. The properties of the PET substrate areits very high melting point above $254^{\circ} \mathrm{C}$ which is the reason for it having high thermal stability. Commercial available PET has rough surface quality, because of which before using the material it is advisable to clean the surface with acetone and ethanol at room temperature [12].

\section{Rogers 4350}

Rogers 4350 is a type of substrate material that are woven glass reinforced ceramics with excellent electrical performance. The substrate possesses excellent impedance transmission lines, which is the vital parameter needed for RFID antenna design [13], apart from the fact that designers can design filters, coupling networks etc which is the characteristics required for RF microwave design [14]. RT Duroid 4350 substrate has low loss tangent and can be used in applications where very high frequency operation is required. The low temperature coefficient, and stable dielectric constant makes it useful for broadband applications. It has a TG of more than $280^{\circ} \mathrm{C}$, because of which its mechanical strength remains stable during the process of fabrication and can withhold high temperature soldering. The various benefits offered by using the Rogers substrate is its low electrical loss, low moisture absorption rate, and high thermal stability over wide range of frequency.

\section{Taconic TLY}

Taconic TLY substrates are specifically designed with

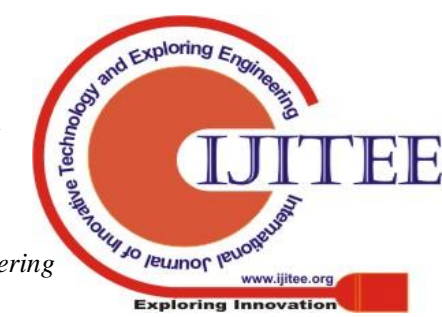


very light weight woven fiberglass and dimensionally very stable. The way the substrate is being manufactured using woven technique it results in a more mechanical stable laminate used for high volume manufacturing. The dielectric constant for Taconic substrate ranges from 2.17 to 2.40 [15]. TLY products with newly enhanced flexibility has also been designed for applications that need flexibility in its shape. The choice of Taconic substrate is also attractive from cost-performance ratio factor, dimensionally stable, low moisture absorption, having low density (1.92 g/cm3), excellent peel strength, and compatible with flat copper.

The major parameters of the substrate used for determining the characteristics of the antenna parameter is shown below in table I.

Table I. Parameter Value for Different Substrate Materials

\begin{tabular}{|c|c|c|c|c|}
\hline Parameter & FR4 & PET & $\begin{array}{c}\text { Rogers } \\
\mathbf{4 3 5 0}\end{array}$ & $\begin{array}{c}\text { Taconic } \\
\text { TLY }\end{array}$ \\
\hline $\begin{array}{c}\text { Dielectric } \\
\text { constant, } \varepsilon_{r}\end{array}$ & 4.3 & 3.2 & 3.6 & 2.2 \\
\hline $\begin{array}{c}\text { Loss tangent, } \\
\text { tand }\end{array}$ & 0.002 & 0.003 & 0.004 & 0.0009 \\
\hline Height $(\mathrm{mm})$ & 1.6 & 0.009 & 0.762 & 0.13 \\
\hline
\end{tabular}

\section{TAG ANTENNA DESIGN}

The geometry of the proposed UHF RFID tag antenna is shown in fig.2, which consists of a meandering dipole antenna, mounted on a substrate material (FR4/ PET/ Rogers 4350/ Taconic TLY).

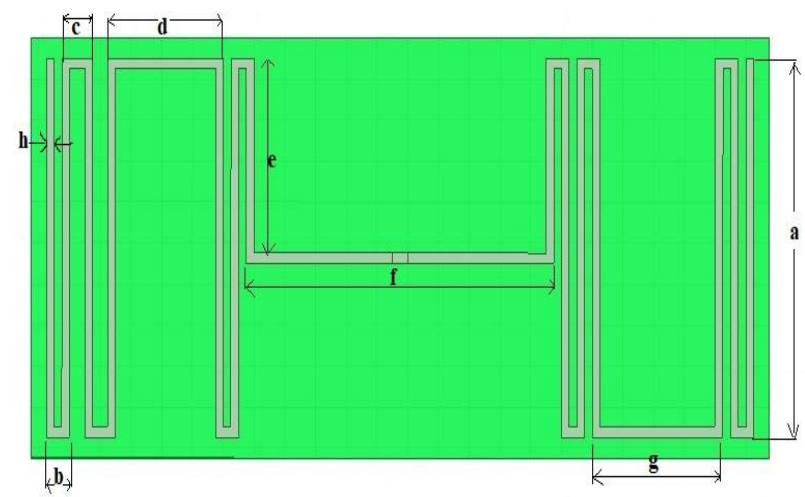

Fig. 2 Tag Antenna Geometry Proposed

Meandering type antenna is used to miniaturize the size of the tag antenna, by folding the antenna length back and forth increasing its resonant length without increasing the physical size [16]. Olusola et al mentioned that keeping the total length of the antenna constant and varying height, if the number of turns of the meander is increased, the overall capacitance of the antenna decreases while the inductance remains constant and the resonant frequency increases.

Again, with constant height fixed and length allowed to increase, it results in increase in inductance and the resonant frequency has an inverse effect on the number of turns of the antenna. By varying the parameters of meander width, length, and number of turns, the tag antenna can be tunes to the resonant frequency at UHF RFID frequency band of 866 $\mathrm{MHz}$ [17]. The finalized geometry of the tag antenna is shown in table II. The length and width of the substrate is
$48 \mathrm{~mm}$ by $20.5 \mathrm{~mm}$.

Table II. Geometry of the Tag Antenna Structure

\begin{tabular}{|c|c|c|c|c|c|c|c|c|}
\hline $\mathrm{a}$ & $\mathrm{b}$ & $\mathrm{c}$ & $\mathrm{d}$ & $\mathrm{e}$ & $\mathrm{f}$ & $\mathrm{g}$ & $\mathrm{h}$ & $(\mathrm{mm})$ \\
\hline 18.5 & 1 & 2 & 6.5 & 10 & 19 & 7.5 & 0.5 & \\
\hline
\end{tabular}

The RFID chip used with this tag antenna, is the Aliens Higgs-4 chip whose impedance value was calculated to be

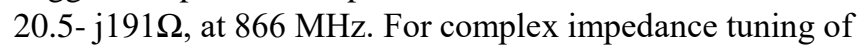
the proposed tag antenna with the RFID chip, a matching stub circuit is introduced at the center of the antenna. Hence the matching circuit used here, is the T-match circuit, that acts as an impedance transformer allowing the input impedance to be inductive.

The geometrical parameters of the T-match structure- T1, $\mathrm{T} 2$ and $\mathrm{T} 3$,can be tuned for matching the antenna impedance with the chip impedance [18]. The next section has the details of antenna designs using different substrates for UHF RFID tag applications. From fig. 3(a) - fig. 3(d), it shows the final antenna parameter after achieving the complex impedance matching.

\section{A. FR-4}

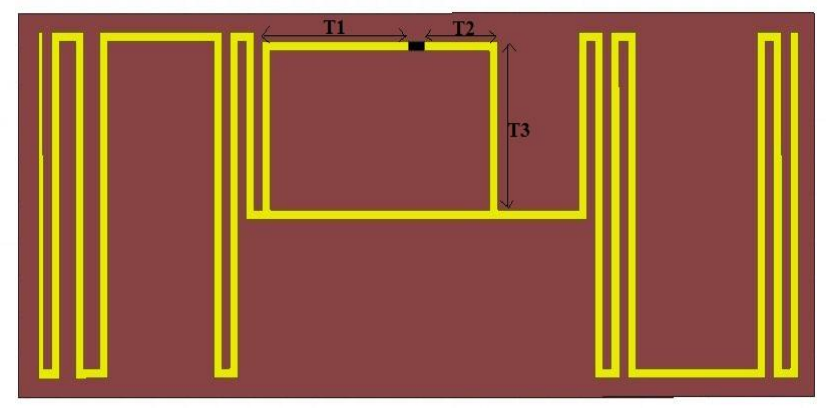

Fig 3. (a) FR-4 Based Tag Antenna

\section{B. PET}

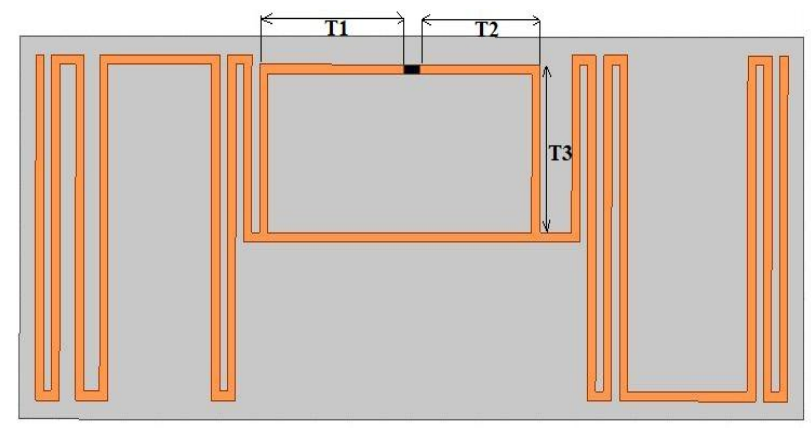

Fig 3. (b) PET Based Tag Antenna

\section{Rogers 4350}




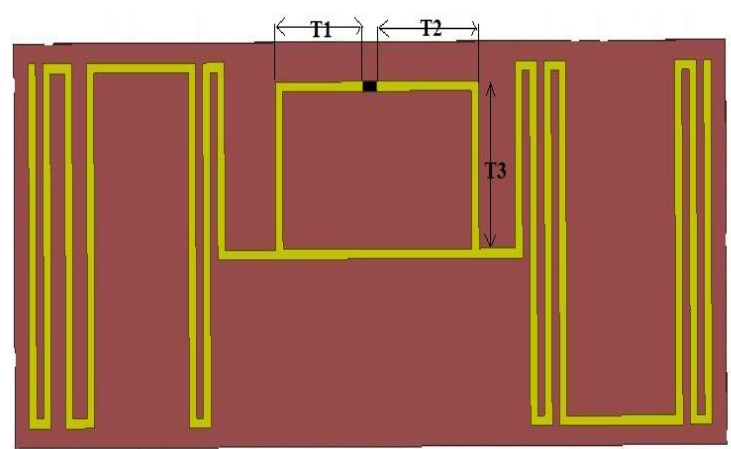

Fig 3. (c) Rogers 4350 Based Tag Antenna

\section{Taconic TLY}

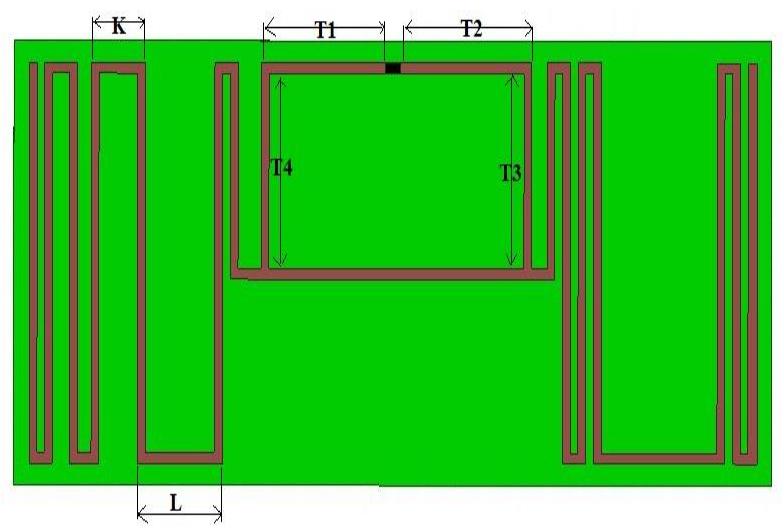

Fig 3. (d) Taconic Based Tag Antenna

The final dimensions of the tag antenna parameter design after using T-match stub for different substrates after conjugate matching is summarized in table III. Some substrates tend to shift their operating frequency after chip normalization because of which the original tag dimension are altered and have to be remodified. From table III. It can be seen that for FR4 (parameter ' $h$ ' in $\mathrm{mm}$ ) and Taconic TLY (parameter ' $\mathrm{K}$ ' and ' $\mathrm{L}$ ' in $\mathrm{mm}$ ) substrates, these dimensions are altered to obtained the desired resonant frequency at 866 $\mathrm{MHz}$.

Table III. Final Parameter of the Antenna Using Different Substrate Materials

\begin{tabular}{|c|c|c|c|c|c|c|}
\hline $\begin{array}{c}\text { Para- } \\
\text { meter }\end{array}$ & $\begin{array}{c}\text { T1 } \\
(\mathbf{m m})\end{array}$ & $\begin{array}{c}\text { T2 } \\
(\mathbf{m m})\end{array}$ & $\begin{array}{c}\text { T3 } \\
(\mathbf{m m})\end{array}$ & $\begin{array}{c}\mathbf{K} \\
(\mathbf{m m})\end{array}$ & $\begin{array}{c}\mathbf{L} \\
(\mathbf{m m})\end{array}$ & $\begin{array}{c}\mathbf{h} \\
(\mathbf{m m})\end{array}$ \\
\hline FR4 & 9 & 4.5 & 8.5 & -- & -- & 0.3 \\
\hline PET & 9 & 7.5 & 8.5 & -- & -- & -- \\
\hline $\begin{array}{c}\text { Rogers } \\
\text { 4350 }\end{array}$ & 6 & 7 & 8 & -- & -- & -- \\
\hline $\begin{array}{c}\text { Taconic } \\
\text { TLY }\end{array}$ & 8 & 8.5 & 9 & 2.5 & 4.5 & -- \\
\hline
\end{tabular}

\section{SIMULATION RESULTS AND DISCUSSION}

The parameters such as reflection coefficient, gain, impedance matching, Voltage Standing Wave Ratio, directivity etc. are some of the important factors in determining the performance of the tag antenna and correspondingly, its read range. Since the performance of four different substrates has to be compared, during simulation two same reference factors are considered:

i. The dimensions of the tag antenna are kept fixed for all the different substrate materials used.

ii. For optimization, only the parameter of the T-match structure is to be varied with a coarse variation step size of $0.5 \mathrm{~mm}$ taken. The current division ratio of both the main radiating element and the stub matching circuit are also kept same.

\section{A. Return loss}

Generally, to get a clear view of how much transmitted power is transferred to the RFID chip is measured using the S11 parameter or the reflection coefficient. If all the incident power is absorbed by the chip, the reflection coefficient would tend to have value less than $-10 \mathrm{~dB}$, while a larger $\mathrm{S} 11$ value indicates more power is loss in reflection. Fig 4, shows the return loss value when different substrate materials are used for designing the UHF RFID tag antenna.

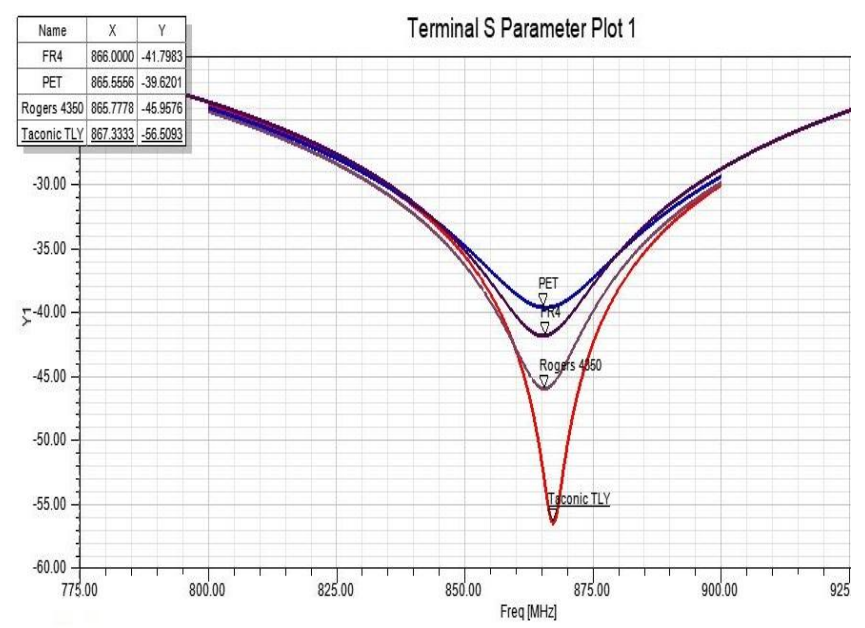

Fig 4. Simulated Result of Return Loss for All the Four Substrates Combined.

From the table IV. comparison, it is seen that using the Taconic substrate it gives the best return loss value of -56.50 $\mathrm{dB}$, while the PET substrate material shows the highest return loss value of $-39.62 \mathrm{~dB}$.

Table IV. Comparison of Return Loss Value.

\begin{tabular}{|c|c|}
\hline Substrate & Return loss (dB) \\
\hline FR4 & -41.79 \\
\hline PET & -39.62 \\
\hline Rogers 4350 & -45.93 \\
\hline Taconic & -56.50 \\
\hline
\end{tabular}

\section{B. Gain}

The antenna gain is simulated to determine how much power by the designed antenna radiates in the direction of the peak radiation as compared to the isotropic antenna. The higher the gain, the better the radio waves received by the tag antenna are converted to the electrical current. However, for RFID system based application mostly the omni-directional antennas are used, hence designing a low gain antennas are much in common.

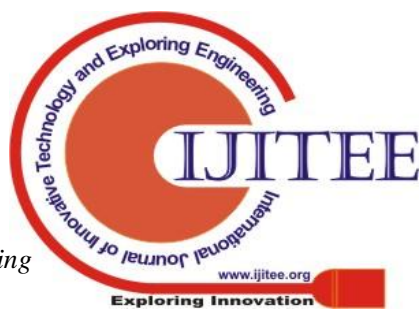



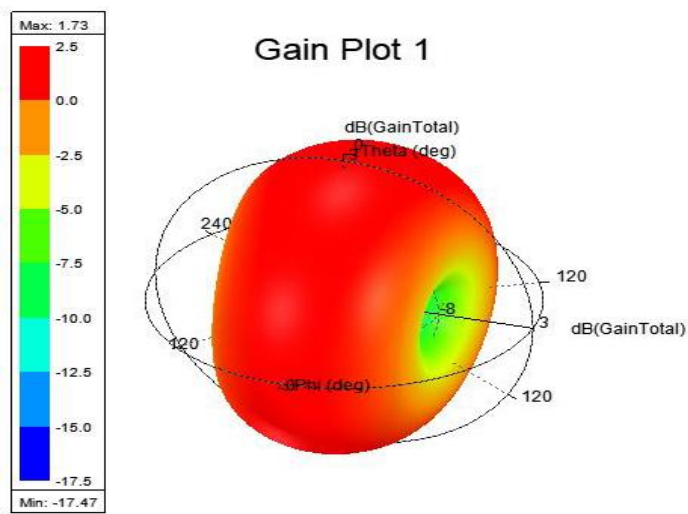

Fig 5 (a). 3D Polar Plot for FR4 Substrate

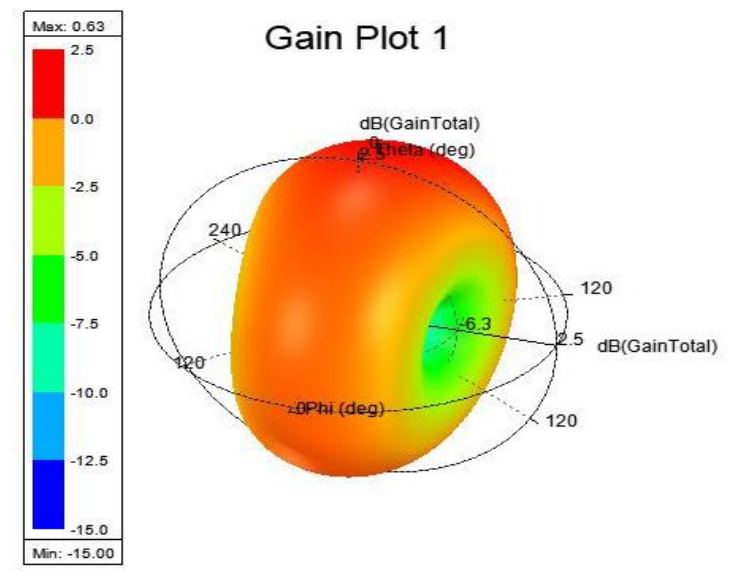

Fig 5 (b).3D Polar Plot PET Substrate

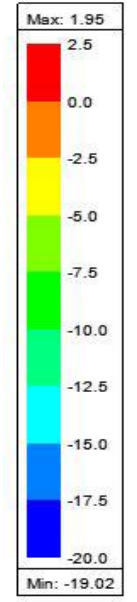

Gain Plot 1

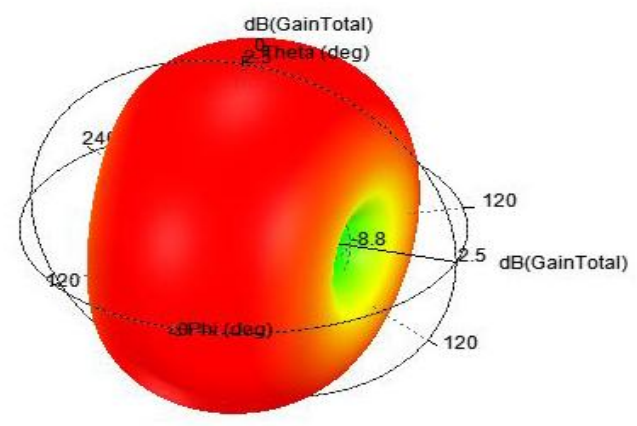

Fig 5 (c).3D Polar Plot for Rogers 4350 Substrate
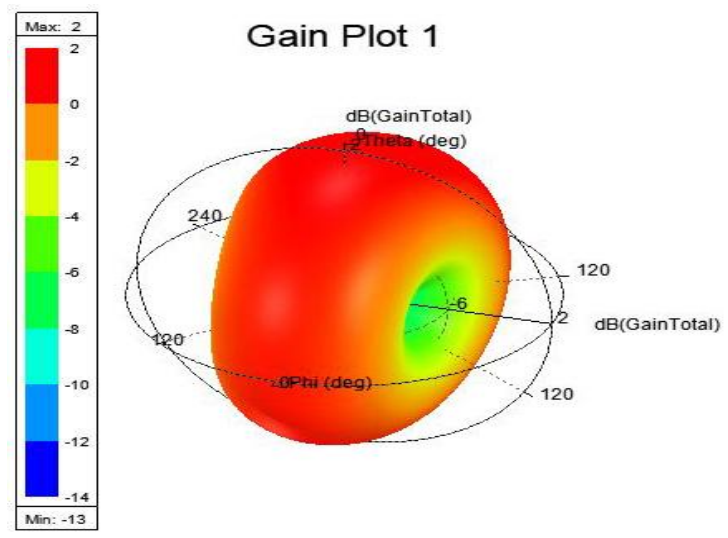

Fig 5 (d).3D Polar Plot for Taconic TLY Substrate
Table V. Antenna Gain comparison table

\begin{tabular}{|c|c|}
\hline Substrate & Gain (dB) \\
\hline FR4 & 1.73 \\
\hline PET & 0.63 \\
\hline Rogers 4350 & 1.95 \\
\hline Taconic & 2 \\
\hline
\end{tabular}

From the table $\mathrm{V}$, the tag antenna using the substrate Taconic gives the maximum antenna gain of $2 \mathrm{~dB}$ in a particular direction and receive $2 \mathrm{~dB}$ more power than a lossless isotropic antenna, while the substrate material using the PET indicates a minimum gain of $0.63 \mathrm{~dB}$.

\section{Impedance matching}

The matching structure parameters; length of the T-match (T1 and T2), and height (T3 and T4) are varied for optimization purpose using the Ansys HFSS simulator to obtain the complex conjugate matching of the tag antenna with the RFID chip. Since the chip impedance is more capacitive, the impedance of the tag antenna has to be made inductive. When the reactance of these two components have equal magnitude with opposite polarity, the tag inductance and chip capacitance cancel each other out leaving only the real resistance part. Hence the goal of this impedance matching technique is the achievement of complex conjugate properties.

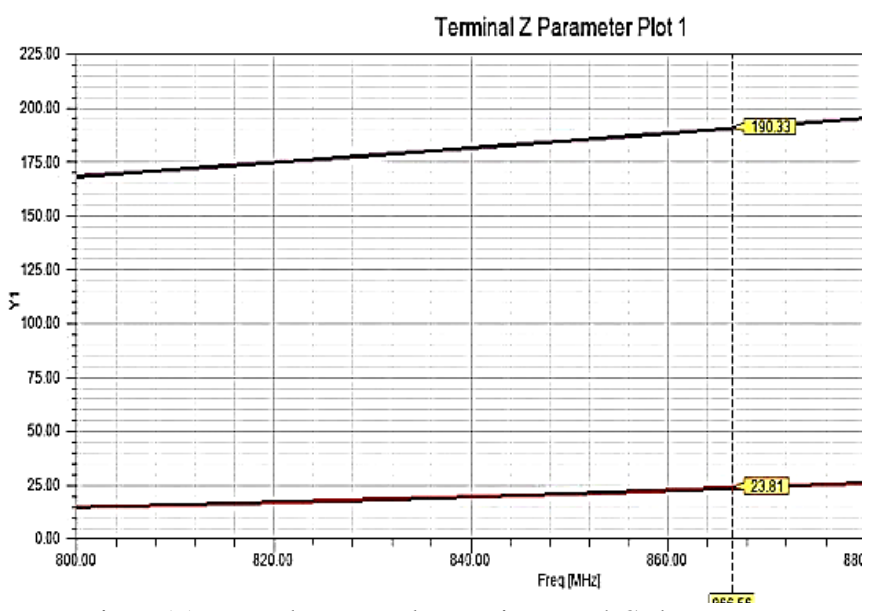

Fig 6.(a) Impedance Value Using FR4 Substrate

Fig 6. (a) shows the impedance of the tag antenna achieved after optimization using the FR4 substrate. By making the height of the T-match structure at $8.5 \mathrm{~mm}$, and the length $\mathrm{T} 1$ and $\mathrm{T} 2$ having the value $9 \mathrm{~mm}$ and $4.5 \mathrm{~mm}$ respectively, the closest impedance achieved to the chip impedance is $23.81+\mathrm{j} 190.33 \Omega$. During optimization, it was found that for low T3 and T4 values, the value of the resistance was very high and inductance very low. When height T3 and T4 increases, the inductance value also increases. When the length $\mathrm{T} 1$ and $\mathrm{T} 2$ becomes shorter, it shows to have an inverse effect on the real resistance. Definitely for FR4 substrate, optimization parameter was not easy to achieve as there were a need to increase the length of the antenna geometry to

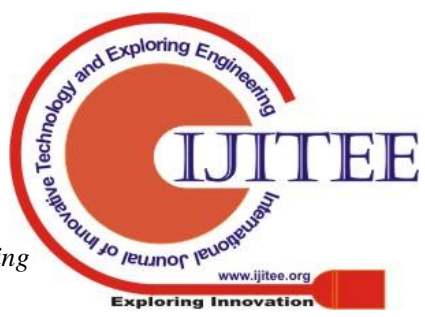


achieve even better match with the chip impedance. For the current study, the antenna geometry confinement was not enough to achieve the conjugate matching accurately. For different number of parameter variation, the number of hits made was only 1 shown in table VI, indicating the bottleneck in freedom of parameter variation with the current set up and the need for micro parameter variation was highly required. After chip normalization, the structure of the tag antenna had to be changed to achieve the resonant frequency, it might be attributed to the fact that since the FR4 relative permittivity is inaccurate, and high loss tangent factor it results in shift of operating frequency.

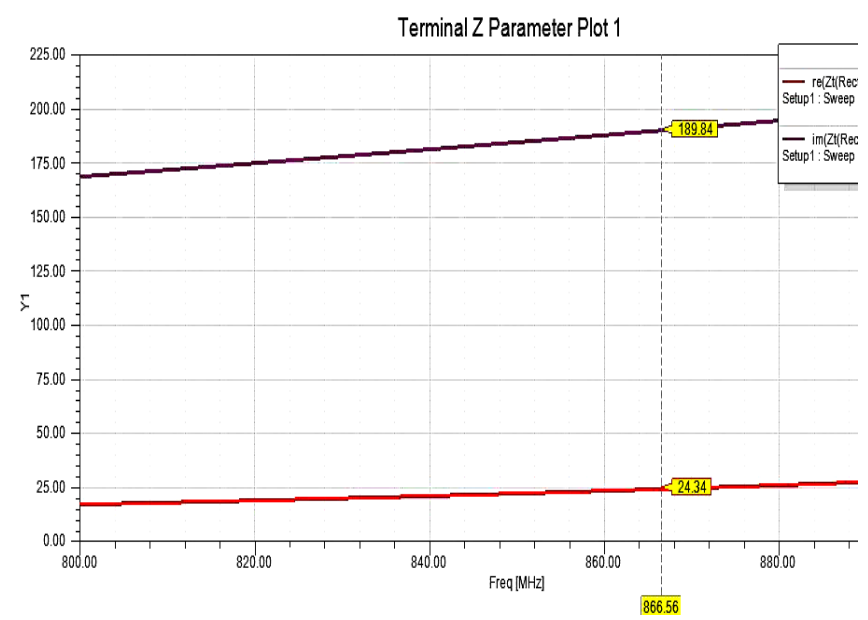

Fig 6. (b) Impedance Value Using PET Substrate

Fig 6. (b) shows the impedance of the tag antenna achieved using the PET substrate. As compared to FR4 substrate, the optimization reading was fairly smooth with the number of hits being 6 . It indicates more freedom in parameter variation for achieving the impedance of the tag antenna to be matched with the RFID chip. With the closest impedance value of $23.34+\mathrm{j} 189.84 \Omega$ achieved with $\mathrm{T}$-match parameter length of $9 \mathrm{~mm}$ and $7.5 \mathrm{~mm}$ for $\mathrm{T} 1$ and $\mathrm{T} 2$ respectively with height $8.5 \mathrm{~mm}$ for $\mathrm{T} 3$ and $\mathrm{T} 4$, there is certainty that with large number of hits if micro optimization is being used better conjugate matching should have been achieved without having to increase the antenna size. After chip normalization, there was no requirement of changing the final structure of the antenna, indicating a very stable structural material.

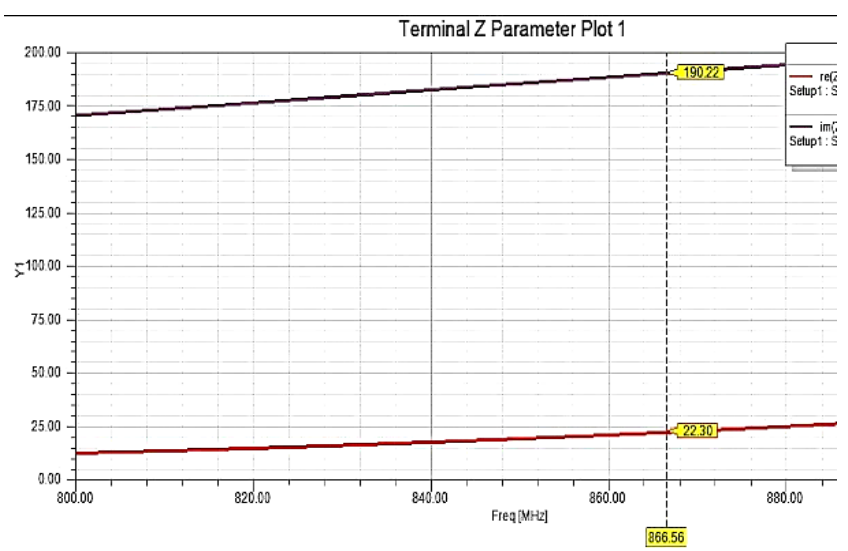

Fig 6. (c) Impedance Value Using Rogers 4350 Substrate

Fig 6. (c) shows the impedance value of the RFID tag using the Rogers 4350 substrate. With the impedance value of $22.30+\mathrm{j} 190.22 \Omega$ achieved, it has the best impedance to be matched with the RFID chip as compared to earlier FR4 or PET substrate. For same criteria of optimization, the number of hits achieved was 9 indicating that the freedom of variable variation was more. Even without the micro parameter variation, the tag antenna impedance achieved is close to the RFID chip indicating a good performance for RFID based application. The T1 and T2 values are $6 \mathrm{~mm}$ and $7 \mathrm{~mm}$, having height of $8 \mathrm{~mm}$. For Rogers 4350 similar to PET substrate, there was no requirement of changing the final structure of the tag antenna after chip normalization proving the low loss material property with low cost.

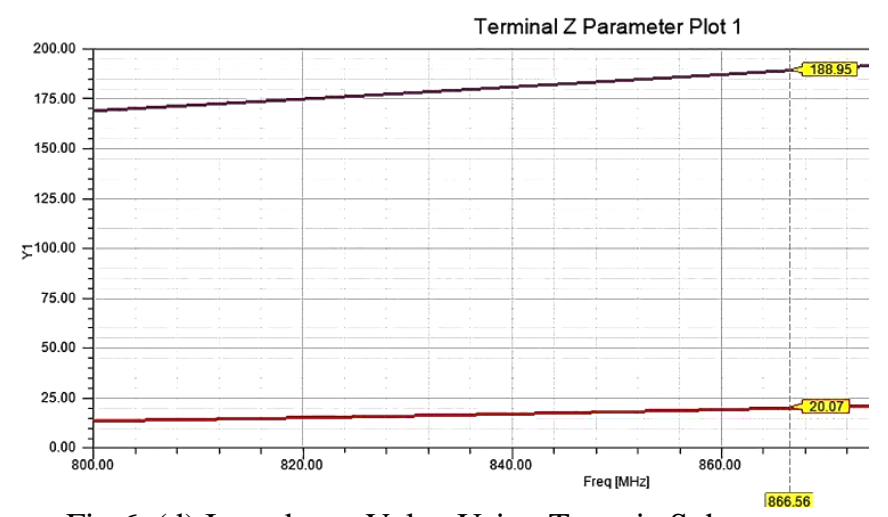

Fig 6. (d) Impedance Value Using Taconic Substrate

Lastly, the fig 6. (d) shows the plot of impedance of the tag antenna using Taconic TLY substrate at $866 \mathrm{MHz}$ frequency operation. The impedance achieved using Taconic TLY substrate was found to be the best match among the rest of the substrate. After optimization the final parameter value is $\mathrm{T} 1=8 \mathrm{~mm}, \mathrm{~T} 2=9 \mathrm{~mm}$, height having the value $9 \mathrm{~mm}$. It has been observed that using the Taconic TLY substrate, results in very high value of reactance and awkwardly low resistance value. Such kind of substrate can be used where the chip impedance has very high capacitor value with low resistance values. Increasing the height of the T-match structure has a visible change in impedance as compared to the length of the antenna, since for shorter T1 and T3 value the impedance becomes nearly constant.

Table VI. Comparison Table for Impedance Matching with the Chip Impedance

\begin{tabular}{|c|c|c|c|c|c|}
\hline $\begin{array}{l}\text { Sub- } \\
\text { strate }\end{array}$ & $\begin{array}{l}\text { Chip } \\
\text { Imp- } \\
\text { edanc } \\
\text { e }\end{array}$ & $\begin{array}{c}\text { Antenna } \\
\text { Impedanc } \\
\mathrm{e}\end{array}$ & $\begin{array}{c}\text { Variation } \\
\text { factor }\end{array}$ & $\begin{array}{c}\text { No } \\
\text { of } \\
\text { hit } \\
\text { s }\end{array}$ & $\begin{array}{l}\text { Freq. } \\
\text { Shift } \\
\text { After } \\
\text { Chip } \\
\text { Norm } \\
\text { - } \\
\text { alizati } \\
\text { on }\end{array}$ \\
\hline FR4 & \multirow{4}{*}{ 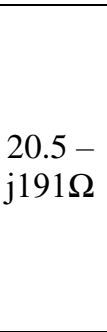 } & $\begin{array}{c}23.81+ \\
\mathrm{j} 190.33 \Omega\end{array}$ & $\begin{array}{c} \pm 3.3 \pm \\
\text { j0.67 }\end{array}$ & 1 & Yes \\
\hline PET & & $\begin{array}{c}24.34+ \\
\mathrm{j} 189.84 \Omega\end{array}$ & $\begin{array}{c} \pm 3.84 \pm \\
\mathrm{j} 1.16\end{array}$ & 6 & No \\
\hline $\begin{array}{c}\text { Rogers } \\
4350\end{array}$ & & $\begin{array}{c}22.30+ \\
\mathrm{j} 190.22 \Omega\end{array}$ & $\begin{array}{c} \pm 1.8 \pm \\
\mathrm{j} 0.78\end{array}$ & 9 & No \\
\hline $\begin{array}{l}\text { Taconic } \\
\text { TLY }\end{array}$ & & $\begin{array}{c}20.07+ \\
\mathrm{j} 188.95 \Omega\end{array}$ & $\begin{array}{c} \pm 0.43 \pm \\
\mathrm{j} 2.05\end{array}$ & 10 & Yes \\
\hline
\end{tabular}


The number of hits is based on the closeness of the tag antenna impedance value achieved with the chip impedance for an acceptable variation of either \pm 5 value. For different optimization performed with relation to the before mentioned criteria of reference, when the antenna impedance (both resistance and reactance) achieved is around \pm 5 value with relation to the chip impedance, it is considered to be counted in the number of hits columns. It indicates how many times the antenna impedance value can be achieve closely with the chip impedance for the set parameter optimization process. The more the number of hits, the better there is a chance of the antenna hitting the accurate complex impedance. As is evident form the table VI, the Taconic TLY has the most number of hits at 10, and as compared with the desired chip impedance, it conversely has the best conjugate matching from all the remaining substrate. Followed next, is the Rogers 4350 with 9 number of hits having the next best impedance matching value.

The PET substrate material was found to have the larger variation with the desired impedance value. After chip normalization, Taconic TLY substrate was the most difficult to achieve resonant frequency compared to the remaining substrates, because of its least loss tangent factor and the tag antenna structure has to be changed.

\section{VSWR}

Voltage Standing Wave Ratio as the name suggest is the measure of mismatch between the tag antenna and the RFID chip, and can determine the impedance matching accuracy of the design. For calculation of VSWR, it should consist of both the real resistance and the impedance comprising a complex number. When the antenna is matched with the chip, more power is delivered and the value of VSWR becomes minimum. In ideal case, no power should be reflected back and the value of the VSWR should be minimum at 1 . VSWR of less than 2 are preferred naturally [19].

Fig. 7 shows the VSWR reading of different substrate materials used for designing of tag antenna.The VSWR value depends upon the impedance matching factor, and from the table VII. during simulation it is seen that the Taconic substrate gives a perfect VSWR ratio. While the PET and FR4 substrate has shown a decreased VSWR value of 1.02 .

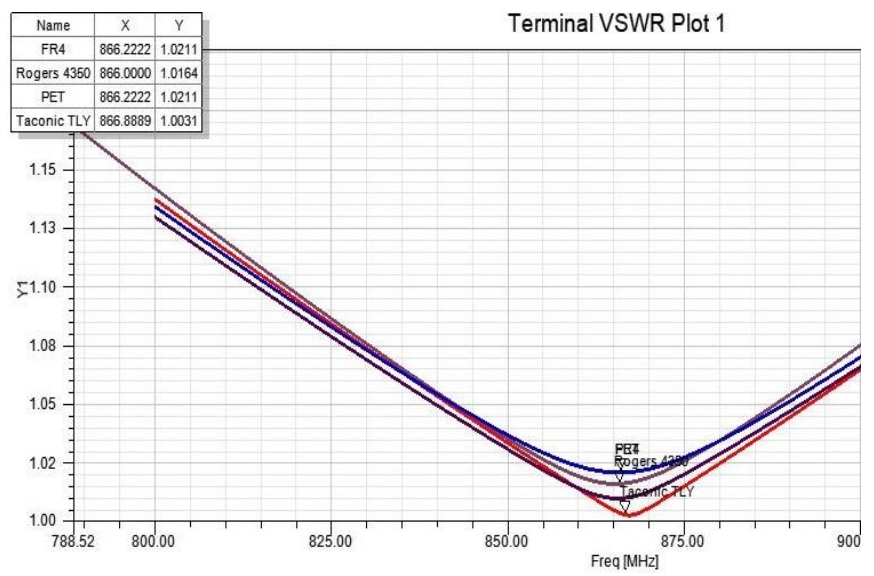

Fig.7 Plot of VSWR Value Measured for all the Four Substrates
Table VII. VSWR Value Comparison for Different Substrates

\begin{tabular}{|c|c|}
\hline Substrate & VSWR value \\
\hline FR4 & 1.02 \\
\hline PET & 1.02 \\
\hline Rogers 4350 & 1.01 \\
\hline Taconic TLY & 1.00 \\
\hline
\end{tabular}

\section{E. Read range}

The read range can be calculated using Friis free space equation as given below [20]:

$$
r=\frac{\lambda}{4 \pi} \sqrt{\frac{\mathrm{P}_{\mathrm{r}} \mathrm{G}_{\mathrm{r}} \mathrm{G}_{\mathrm{a}} \tau}{\mathrm{P}_{\mathrm{th}}}}
$$

where, $\lambda=$ wavelength, $P_{r} G_{r}=$ EIRP of the reader, $\mathrm{P}_{\text {th }}=$ threshold power sensitivity of the chip,

$\mathrm{G}_{\mathrm{a}}=$ gain of the antenna, $\tau=$ power transmission coefficient

Power transmission coefficient formulae is shown as [21]: $\tau=\frac{4 \mathrm{R}_{\mathrm{a}} \mathrm{R}_{\mathrm{c}}}{\left\langle\mathrm{Z}_{\mathrm{a}}+\mathrm{Z}_{\mathrm{c}}\right\rangle^{2}}$

For read range calculation, lets assume the following values:EIRP: $4 \mathrm{~W}$, Pth: $-18.5 \mathrm{dBm} . \lambda=0.346 \mathrm{~m}$ (resonant frequency of $866 \mathrm{MHz}$ )

\section{- $F R-4$}

For FR4, $\mathrm{Z}_{\mathrm{a}}=23.81+\mathrm{j} 190.33 \Omega$, and $\mathrm{Z}_{\mathrm{c}}=20.55-\mathrm{j} 191 \Omega$ Calculating for power transmission coefficient, we get $\tau=$ $99.4 \%$. Using the read range formulae of (2) for UHF RFID application, it is estimated at the value of 17.8 meter.

\section{- $\quad$ PET}

For PET substrate, $\mathrm{Z}_{\mathrm{a}}=24.34+\mathrm{j} 189.84 \Omega$, and $\mathrm{Z}_{\mathrm{c}}=20.55-$ j191 $\Omega$. Calculating for power transmission coefficient, the value obtained is $99.2 \%$.

The read range obtained for UHF RFID application using (2) were calculated at the range of 15.6 meter.

\section{- Rogers 4350}

For Rogers 4350 substrate, $\mathrm{Z}_{\mathrm{a}}=22.3+\mathrm{j} 190.22 \Omega$, and $\mathrm{Z}_{\mathrm{c}}=$ 20.55 - j191 $\Omega$. Calculating for power transmission coefficient, its value were $99.8 \%$.

The read range obtained for UHF RFID application using (2) is 18.2 meter.

\section{- Taconic TLY}

For Taconic TLY substrate, $\mathrm{Z}_{\mathrm{a}}=20.07+\mathrm{j} 188.95 \Omega$, and $\mathrm{Z}_{\mathrm{c}}=$ 20.55 - j191 $\Omega$. Calculating for power transmission coefficient, the value obtained is $99.7 \%$.

The read range obtained for UHF RFID application using (2) were found to be at the range of 18.4 meter.

Published By: 


\section{COMPARISON OF ANTENNA PARAMETER FOR DIFFERENT SUBSTRATES FIGURES AND TABLES}

The table VIII. is given below in which values for different parameters are given for all the substrates considered indicating the performance analysis of the substrates.

Table VIII. Comparison Table for Different Antenna Parameters using Different Substrates.

\begin{tabular}{|c|c|c|c|c|}
\hline \multirow{2}{*}{ Parameter } & \multicolumn{4}{|c|}{ Substrate } \\
\cline { 2 - 5 } & FR4 & PET & $\begin{array}{c}\text { Rogers } \\
\mathbf{4 3 5 0}\end{array}$ & Taconic \\
\hline $\begin{array}{c}\text { Return loss } \\
\text { (dB) }\end{array}$ & -41.79 & -39.62 & -45.93 & $\mathbf{- 5 6 . 5 0}$ \\
\hline Gain (dB) & 1.73 & 0.63 & 1.95 & $\mathbf{2 . 0}$ \\
\hline $\begin{array}{c}\text { Impedance } \\
\text { matching }\end{array}$ & $\begin{array}{c}23.81+ \\
\mathrm{j} 190.33 \\
\Omega\end{array}$ & $\begin{array}{c}24.34+ \\
\mathrm{j} 189.84 \\
\Omega\end{array}$ & $\begin{array}{c}\mathrm{j} 190.3+ \\
\Omega\end{array}$ & $\begin{array}{c}\mathbf{2 0 . 0 7}+ \\
\mathbf{j 1 8 8 . 9 5} \\
\mathbf{\Omega}\end{array}$ \\
\hline $\begin{array}{c}\text { VSWR } \\
\text { VSW }\end{array}$ & 1.02 & 1.02 & 1.01 & $\mathbf{1 . 0 0}$ \\
\hline $\begin{array}{c}\text { Radiation } \\
\text { efficiency }\end{array}$ & $83.3 \%$ & $62.4 \%$ & $\mathbf{8 9 . 9 \%}$ & $77.7 \%$ \\
\hline $\begin{array}{c}\text { Maximum } \\
\text { directivity }\end{array}$ & 1.7858 & $\mathbf{1 . 8 5 3 1}$ & 1.7413 & 1.8222 \\
\hline $\begin{array}{c}\text { Theoretical } \\
\text { Read range } \\
\text { (m) }\end{array}$ & 17.8 & 15.6 & 18.2 & $\mathbf{1 8 . 4}$ \\
\hline
\end{tabular}

\section{CONCLUSION}

Four different substrates: FR4, PET, Rogers 4350, and Taconic TLY, that are most commonly used for the fabrication of tag antenna in UHF RFID design application has been studied in this paper. From above analysis, it is concluded that the least return loss of $-56.50 \mathrm{~dB}$ result was achieved in Taconic TLY substrate at thickness of $0.13 \mathrm{~mm}$. The PET substrate, even though it had the thinnest substrate thickness of only $0.009 \mathrm{~mm}$, it showed the largest return loss value of $-39.62 \mathrm{~dB}$ when compared with the rest of the substrate. For the same substrate size, but with varying thickness the antenna gain was found to be maximum for Taconic TLY substrate at $2 \mathrm{~dB}$, while the gain was lowest for PET substrate. For PET since it has the least height of $0.009 \mathrm{~mm}$, so the gain was bound to be lower; but FR4 with the highest height of $1.6 \mathrm{~mm}$, it could achieve the gain of only $1.73 \mathrm{~dB}$. While for VSWR, since the PET was most closely impedance matched with the chip, it showed the best VSWR rating. The overall best performance was found to be in the case of Rogers 4350 material as it has the best radiation efficiency of $89.9 \%$. In case of antenna directivity, even though using PET substrate gave the least antenna performance parameter overall, it had the best directivity of 1.85. This is an important factor in antenna size miniaturization, where most design are focused on increasing the size of the antenna to improve the directivity. Therefore, for a miniaturized antenna with better directivity, the PET substrate material gave the best option. Read range the most important factor for UHF RFID tag antenna design, using Taconic TLY substrate from among the rest of the substrate materials gave the longest theoretical calculation of $18.4 \mathrm{~m}$, followed by Rogers 4350 with $18.2 \mathrm{~m}$. These results are obtained with the help of Ansys HFSS simulator, where fabrication measurement is left for the future analysis. No substrate is universally suited for giving the best result for all the antenna parameters. There is always a sacrifice to be made in choosing some parameter over other such as Taconic TLY has the best read range, gain, and VSWR; while the Rogers 4350 has the best radiation efficiency; PET substrate with the maximum directivity, and FR4 having decent return loss and radiation efficiency. Further this study will be helpful for choosing the right substrate according to the application required for passive UHF RFID tag antenna design.

\section{REFERENCES}

1.ALN-9762 Short Inlay Technical Data Sheet, Alien Technology Co. USA.

2. Jasmin Grosinger,Walther Pachler,and Wolfgang Bosch, "Tag sizematters", IEEE Microwave Magazine, Vol. 19, No.6, 2018, pp.101-111.

3. Y. He, X. Zhao, C. Zhang, and Z. Wang, "A fully Integrated Chip- ID tag used in chip information identification," in Proc. IEEE Int.Conf. Radio Frequency Identification, 2012, pp. 172-176.

4. P. Bhartia, I. Bahl, R. Garg, and A. Ittipiboon, Microstrip Antenna Design Handbook. Boston, MA: Artech, 2000, pp. 759-761.

5.C. A. Balanis, Antenna Theory, Analysis and Design, Second Edition, New York, John Wiley \&Sons Inc., 1997,pp. 771-775.

6. A. Khan and R. Nema, "Analysis of five different dielectric substrates on microstrip patch antenna," Int. J. Comput. Appl., Vol. 55, No. 14, 2012, pp. 6-12.

7. Wee FwenHoon, Yew Been Seok, Mohamed Fareq Abdul Malek, Lee Yeng Seng,SitiZuraidah Ibrahim, "Radio Frequency Identification (RFID) tag antenna design at Ultra High Frequency (UHF) band", Indian Journal of Science and Technology, Vol 10, 2017, pp. 1-6.

8. Nanassy. A. I, "Dielectric measurement of moist wood in a sealed system.", Wood Sci. Technol., Vol. 6, 1972, pp. 67-77.

9. A Guide to FR4: When Can You Use It and When Can You Not, Millennium Circuits Limited.

10.Diego Betancourt, and Joaquin Castan, "Printed antenna on flexible low-cost PETsubstrate for UHF applications", Progress In Electromagnetics Research C, Vol. 38, 2013, pp. 129-140.

11.M. G. Faraj, K. Ibrahim, M. K. Ali, "PET as a plastic substrate for the flexible optoelectronic applications", Optoelectronics And Advanced Materials - Rapid Communications, Vol. 5, No. 8, 2011, pp. 879-882.

12.Nhan Ai Tran, Huy Nam Tran, Mau Chien Dangand Eric Fribourg-Blanc, "Copper thin film for RFID UHF antenna on flexible substrate", Advances In Natural Sciences: Nanoscience And Nanotechnology, Vol.1, 2010, pp.1-6.

13.RO4000 Series Laminated Data Sheet, Rogers Corporation, pp. 1-4

14.Rogers Material PCB- Rogers 4350, Rayming PCB \& Assembly.

15.TLY Family of Low Loss Laminates, Taconic.

16.Olusola O. Olaode, W. Devereux Palmer, William T. Joines, "Characterization of meander dipole antennas with a geometry-based, frequency- independent lumped element model", IEEE Antennas And Wireless Propagation Letters, Vol. 11, 2012, pp. 346-349.

17.A.Abattouy, M. Y. Douieb, M.A. Ennasar, O. EL Mrabet, K. Ameziane, "Design of a low cost meander line RFID tag antenna using 3D printing technology", International Conference on Multimedia Computing and Systems, 2018, pp.1-3.

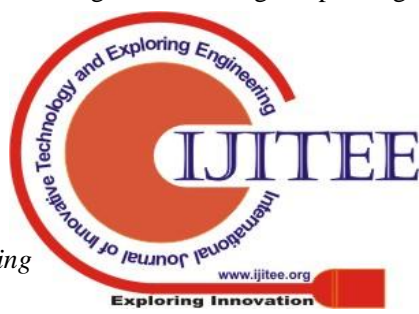


18.Gaetano Marrocco, "The art of UHF RFID antenna design: Impedance-matching and size-reduction techniques", IEEE Antennas and Propagation Magazine, Vol. 50, No. 1, 2008, pp. 66-79.

19.D. Prabhakar, CH. Balaswamy, M. AkhilPoorvika, M. Venkata Krishna Sai, M. Subba Naidu, "Flexible Microstrip Patch Antenna using Different Substrates for Bio- Medical Applications",International Journal of Innovative Technology and Exploring Engineering, Vol. 8, No. 7,2019pp.1350-1352.

20.Lingfei Mo and Chenyang Li, "Double loop inductive feed patch antenna design for antimetalUHF RFID tag", International Journal of Antennas and Propagation, Vol. 2019, pp. 1-9.

21.Ying She, Tao Tang, Guang Jun Wen, Hao Ran Sun, "Ultra-High-Frequency Radio Frequency Identification tag antenna applied for human body and water surfaces", International Journal of RF and Microwave Computer Aided Engineering, Vol. 29, 2018, pp. 1-8.

\section{AUTHORS PROFILE}

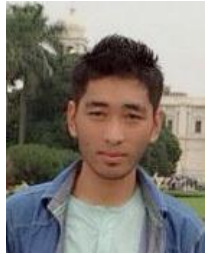

P Limameren Chang presently working as a Lecturer in ICIT, Mokokchung, under the Directorate of Technical Education, Kohima, Nagaland, India. He is currently pursuing Master of Engineering degree in Electronics and Communication Engineering from NITTTR, Punjab University, Chandigarh, India.

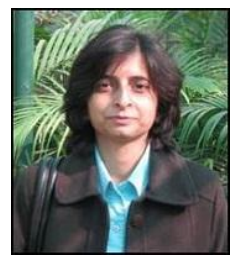

Garima SainiIn 2006, she joined the department of Electronics \& Communication Engineering at NITTTR Chandigarh. Her research interests include, Wireless and Mobile Communication and Antenna design. She has authored more than 50 publications in research journals and conferences. More than 30 M.E. Students completed their thesis under her guidance. She is member of various professional societies. 